\title{
Using Electronic Assessment System in Higher Education: Challenges and Solutions for Lectures, Students and Institutions
}

\author{
Pingkan Imelda Wuisan, Basuki Wibawa
}

\begin{abstract}
Assessment is an important component of education especially in the context of the learning and teaching environment. In higher education, assessment is the heart of formal education. Nowadays, technology plays an important role in the assessment process. Therefore, using technology development has an impact on improving the assessment system. Focus on the using of electronic assessment (e-assessment) systems is increasingly developing at the higher education level. Technological developments have led to a shift in concepts and ways of assessing moving from face-to-face assessment to digital-based assessment, namely an end-to-end assessment process using ICT. E-assessment system is provides many benefits for the effectiveness and efficiency of learning in higher education for lecturers, students and institutions. Many e-assessment models are developed to meet various objectives, especially in the purpose of educational learning. However, there are many challenges in its process and application. This paper aims to provide an example of e-assessment system application, describe challenges in the use of e-assessment systems in higher education based on literature, journals and research results and provide recommendations on how to deal with all of these challenges so that the assessment objectives can be achieved. The method that used is to figure out and describe qualitatively. Overall conclusion is the e-assessment system has become one of the requirements in higher education with many models. There are still many questions for lecturers, students and institutions that pose challenges in the application of e-assessments related to validity and reliability, accuracy, fairness, security, infrastructure and human resources. Based on this fact then the recommendation of these challenges in the successful implementation of e-assessment in higher education are paying attention to the characteristics of e-assessment, designing assessments according the needs, and creating a complete and accessible assessment system for all.
\end{abstract}

Index Terms: Assessment; E-Assessment; E-Assessment System; E-Assessment Challenges; Higher Education; Technology.

\section{INTRODUCTION}

Assessment is a central to educational practice, an important component of education, an essential component in the learning and teaching environment, and the heart of formal higher education (Ridgway, McCusker, \& Pead, 2004; Brink \& Lautenbach, 2011; Crisp, Guàrdia, \& Hillier, 2016; Gikandi, Morrow, \& Davis, 2011). Formal education is held in schools through teaching-learning process, tiered and sustainable from basic education to higher education (Wibawa \& Paidi, 2019). In this process, assessment become significant for educational practices, it should be implemented considerably in schools. In higher education, specifically, the development of technology has been improving its assessments system. There has been a shift in concepts and methods in an assessment system; from traditional assessment to digital assessment. Nowadays, technology plays significant roles in the process of assessment, especially, to evaluate students learning experiences and also to measure their progress academically (Hettiarachchi, Huertas, \& Mor, 2015). That is mean we can not avoid anymore about development of technology because the global demands of industry 4.0 and the fast growth of information technology (IT) infrastructure, very promising in the online education (Asip \& Wibawa, 2019) included in the e-assessment.

Based on some studies done on e- assessment, the use of technology has rapidly been developing in curriculum program in higher education institutions; particularly on the system of assessment. Hench (2014) reported specific studies relate to data-search through the database of Education Resources Information Center (ERIC). He explained that this strategy covers to find abstracts containing e-markers on all types of peer-reviewed publications (journal articles, books, and dissertation) and all levels of education (elementary, middle and college) from 1975 to 2012. There were noted a total of 5022 abstracts identified as containing e-markers. The results obtained can be seen in Fig. 1. 


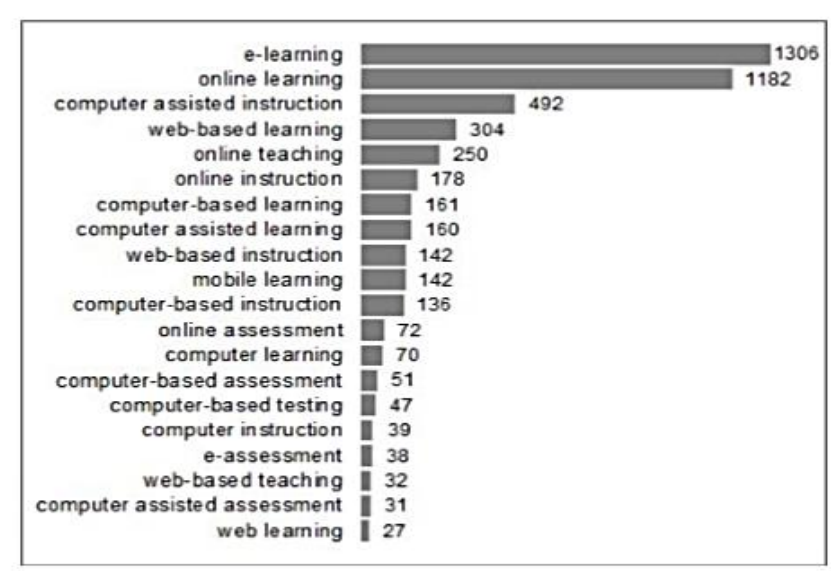

Fig. 1. e-marker frequency over the years 1975 to 2012 (Hench, 2014)

Fig. 1 shows there were 38 studies submitted to ERIC's database compared to e-learning which reached out 1.306 studies between 1975 and 2012. Based on the data, it can be seen that research on e-assessment was extremely less interesting than e-learning. However, research on e-assessment is now growing rapidly and be accepted globally at universities (Bukie, 2014).

Moreover, there are some forms of e-assessment which is designed and developed by experts to serve various purposes of educational assessment. Those forms include administrative procedures, digitizing paper-based systems and online testing, (Alruwais, Wills, \& Wald, 2018), multiple choice question (MCqs), e-SEAT (Selecting and Evaluating e-Assessment Tools) (Singh \& (Ruth) de Villiers, 2017), e-report, e-portfolio, blogs dan forums, e-examination (Bukie, 2014), online discussions, social bookmarking, podcasts, wikis, online group work, and online presentations (Tinoca, Pereira, \& Oliveira, 2014), computer based quizzes (Jordan, 2013).

Regarding to the benefits of e-assessment, some studies revealed the e-assessment itself is potential to help teachers, students, and educational institutions to achieve the goals (Crisp, 2011; Alruwais et al., 2018). Some benefits are including 1) providing instant feedback, 2) decreasing paper-works such as marking, 3) having easier accessibility, 4) reducing time and cost, 5) increasing students comfort, 6) supporting students in reflecting their own learning, and 7) delivering feedback to students (Beevers, 2011; Council for the Curriculum Examination and Assessment, 2018; James, 2016; Khlifi \& El-Sabagh, 2017; Charteris, et al., 2015 ). Some issues also exist in terms of the implementation at universities. Therefore, this paper intends: 1) to provide an example of e-assessment system application, 2) to describe challenges in the use of e-assessment systems in higher education, and 3) to offer some recommendations on how to deal with all of these challenges.

\section{LITERATUR REVIEW}

\section{A. E-assessment System}

E-assessment is the end-to-end electronic assessment processes where ICT is used for any of assessment activity and the recording learners responses. (JISC, 2007; Osuji, 2012). E-assessment involves the use of web-based methods that allow systematic conclusions and assessments of learners' skills, knowledge and abilities (Hettiarachchi et al., 2015). Assessing students' competencies using ICTs, is an important reason for redefining e-assessment, namely the concept of alternative digital assessment strategies that refers to all assessment tasks made possible by technology where design, performance, and feedback must be mediated by technology (Tinoca et al., 2014). It can be said that e-assessment is the process of assessing the knowledge and skills of students using ICT for all assessment procedures ranging from design, implementation, recording of responses and giving feedback that can be seen from the perspective of students, teachers, lecturers and tutors.

The e-assessment system can be identified according to the proposed system context diagram. External entities related to the main system are students, instructors, administrators, and registration units. Students are the main entities that take electronic examinations or assessments. Meanwhile, the instructor is responsible for overseeing or tracking the process. However, the administrator is responsible for managing the entire system, and the registration unit is related to controlling the admissions process for each student's course (Khlifi \& El-Sabagh, 2017).

E-assessment is also a part that is integrated into e-learning systems that are used to assess student knowledge (Ristov et al., 2013). In addition, the e-assessment that depends on learning management systems increases more security issues than other parts of e-learning software (Khlifi $\&$ El-Sabagh, 2017). Therefore, the use of e-assessment is important as a substitute for traditional assessment because assessment can be more student-centric as students by identifying gaps in their learning (Kuikka, Kitola, \& Laakso, 2014). In higher education in the UK there are two types of e-assessment used, namely formative e-assessment and summative e-assessment. Formative e-assessment focuses on ways of e-assessment to support students to start with different levels of knowledge and abilities. Summative e-assessment looks at the experience of using e-assessment for a longer time, has demonstrated the challenges and benefits of low-medium contexts. This is evidenced by more than 80,000 electronic assessments conducted at Loughborough University during 2006 (JISC, 2007)

The use of e-assessment systems does not eliminate the essence of the assessment itself but rather aims to solve many questions and limitations in traditional assessment (Osuji, 2012). The varied and efficient application of e-assessment and innovation reaffirms its potential as a driver in the learning process and learning outcomes (Fontanillas, Carbonell, \& Catasús, 2016). Ras, Whitelock, and Kalz, (2016) in their writing agree that the innovation process for e-assessment can be exploratory and technology driven or driven by the demands of new education and learning practices. Therefore, based on this view, they extract six 
components of innovative e-assessment for learning approaches from the literature and current developments, which include agency change, flexible timing, automation, adaptivity/adaptability, data triangulation, and continuity and dialogue. These six components are used in three case studies that represent innovative future directions for e-assessment and assessment of learning. The three case studies are SAFeSEA project (Supportive Automated Feedback for Short Essay Answers), ubiquitous assessment and feedback, automatic item generation. In the SAFeSEA case study, each of the six innovative e-assessment components received support.

The successful implementation of the e-assessment system is influenced by three factors, namely human, technical and institutional, but the characteristics of the system itself are very important to consider (Isaias, Miranda, \& Pífano, 2017). One of the characteristics of the e-assessment system is about security. To determine whether e-assessment is safe or not, both from the point of view of students as evaluators, it can be asked whether e-assessment has the following properties; 1) Availability. E-assessment is available to be accessed by students and tutors for a predetermined period of time, 2) Integrity. Descriptions of e-assessments (statements, activity descriptions, etc.) must not be changed, destroyed, or lost. Results submitted by students must also have integrity, 3) Identification and authentication. When carrying out evaluation tasks, the facts about what students say must be verified in a reliable way. In addition, the outcome and results of student evaluations must be truly in accordance with the activities that have been carried out by students, 4) Confidentiality and access control. Students will only be able to access the e-assessment that has been prepared specifically for them and the tutor will access after the evaluation process has been established, 5) Non repudiation. LMS must provide protection against false rejection of involvement in e-assessments (Miguel, Caballe, Xhafa, \& Prieto, 2014). In addition, in their writing, Fontanillas et al., (2016) explained the concept of 360 e-assessment characteristics, namely strategic, integral, holistic, transversal, coherent and dynamic. All of these characteristics must be the basis for developing and using e-assessment.

\section{B. Model of E-Assessment System}

Architecturally the e-assessment system has developed for four generations. Ristov et al., (2013) explained the evolution of e-assessment and the entire e-learning process through three different generations and introduced the fourth generation of electronic scoring systems called Eco-systems which can be seen in Figure 2. Here can be said that e-assessment system to accommodate various needs of learning objectives can be developed as technology develops.

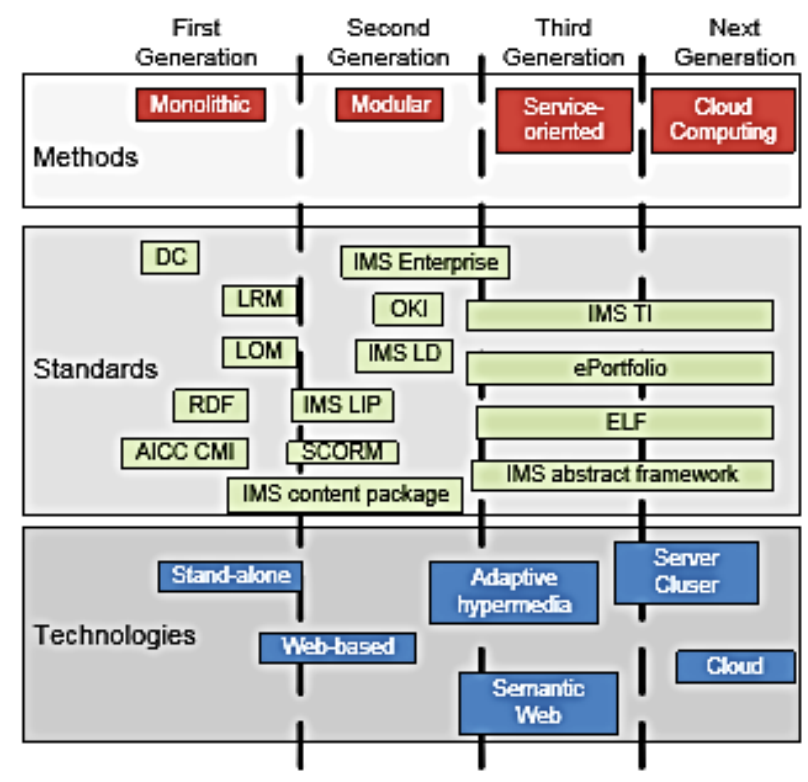

Fig. 2: Four generations of e-Assessment and e-Learning systems (Ristov et al., 2013)

In developing high-quality e-assessment, Tinoca et al., (2014) presents a conceptual framework of e-assessment with assessment criteria specifically how to develop it in the learning landscape in higher education. The framework is described in four dimensions, namely authenticity, consistency, transparency, and practicability. Each dimension is supported by several criteria that are considered important for the validation of competency assessment programs in an online context. This dimension intends to promote the quality of the assessment strategies used and add to the construction of knowledge in the new field of development of quality assessment in an online context.

On the other hand, in their research Isaias et al., (2017) explained the characteristics and principles of an effective assessment system for e-assessments. This framework consists of eight criteria, namely variety of design options, scalability, security, access and usability, feature feedback, personalization, cost and interoperability. To evaluate the effectiveness of these criteria online questionnaires were distributed to 342 respondents, from various countries namely Australia, Brazil, Canada, Colombia, France, Germany, Japan, Mexico, Russia, Spain, Switzerland, the United Kingdom and the United States. Based on the results of the questionnaire it was found that out of the eight criteria, the criteria that had the highest levels of agreement were the variety of design features and the highest levels of disagreement which were costs. These results indicate that to design an e-assessment model, feature design needs to be prioritized.

Some e-assessment system models have been developed, among others, from Whitelock, Reudel, and Mackenzie, (2006) can be seen in Figure 3. They explained how e-assessment can run in a cyclical process. They show that motivation is the main point that drives its application, so this is the first step in the cycle. They emphasize that

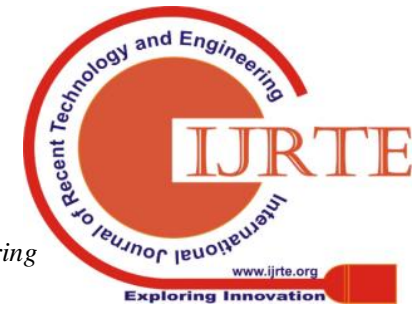


motivation is an important stage in assessment. The next step is design assessment, and then the manufacturing phase. The students start the test and after completion, the results will be delivered. Data are processed and produce feedback. Furthermore, there is an evaluation of the results and feedback review. After this last step, the cycle moves back to the design and manufacturing steps. Testing, data collection or evaluation results, depends on the results and feedback to improve assessment and feedback to meet the objectives and achieve the desired results.

\section{Cycles of e-assessment}

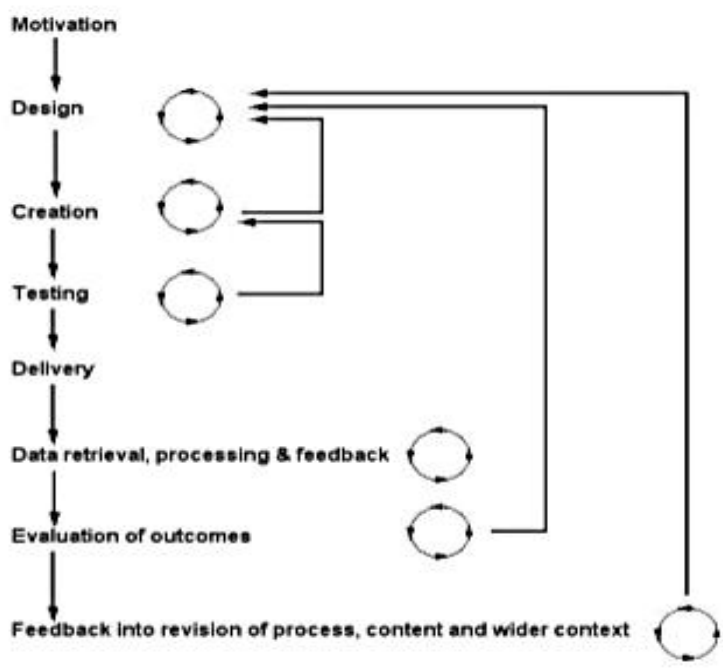

Fig. 3. Cycles of e-assessment (Whitelock, Reudel, \& Mackenzie, 2006)

In fig. 4, Khlifi and El-Sabagh, (2017) identify the main process of the e-assessment system that includes three main processes (pre-e-assessment, during e-assessment, post-eassessment). The diagram involves the flow of system data among recognized sub-processes related to data storage. Pre-e-assessment refers to all processes controlled by the instructor and administrator who facilitate the next process, where the process during e-assessment, it shows all relationships during the e-test or e-assessment process of each student that correlates with the e-server learning, however, the post-e-assessment process correlates with class file storage files.

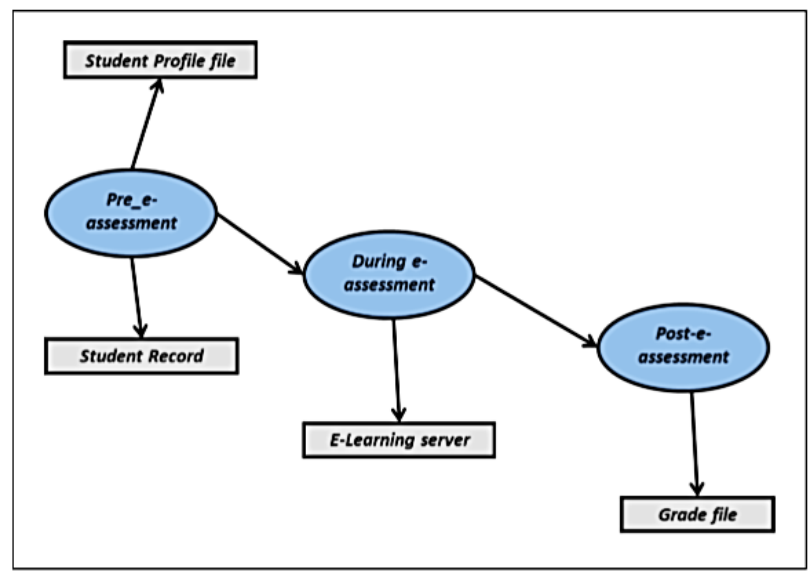

Fig. 4. Main processes of the e-assessment system (Khlifi and El-Sabagh, 2017)
These e-assessment system models illustrate that e-assessments can be developed based on student learning needs and adapted to the institutional context.

\section{E-assessment Challenges}

In addition to the benefits obtained from the implementation of e-assessment, there are challenges faced by lecturer, students, and institutios especially in its application in higher education. The following are e-assessement challenges based on the findings of the researchers:

For lecturers:

- Accuracy and objectivity of the assessment (Ristov et al., 2013)

- E-assessment reliability and validity. Situations that require additional re-assessment due to any kind of assessment obstructions are unacceptable, or how to ensure all students receive equivalent tests if questions are selected at random from a question bank (Ristov et al., 2013; (Oldfield, Broadfoot, Sutherland, \& Timmis, 2012)

- Delivering e-assessments across of many platforms (Byatt, 2014)

- Low level of computer literacy (Osuji, 2012)

For students:

- Security and data privacy issue (Ristov et al., 2013; Miguel et al., 2014; Oldfield et al., 2012)

- Multiple-choice questions (MCQs) and their variants are not always appropriate especially in science and engineering subjects (Beevers, 2011)

For institutions:

- The inappropriateness of technological infrastructures (James, 2016; Osuji, 2012)

- Quality control, (time, cost, instructional design, and staff professional development. (Tinoca et al., 2014)

- E-assessment systems are expensive and not suitable for every type of assessment (Osuji, 2012; Nikolova, 2012)

- Plagiarism detection and invigilation issues, difficulties in scalability and transferability of practices, particularly in higher education when different departments often have autonomous, and lack of staff time and training for rethinking assessment strategies with using new technologies, from a technological and pedagogical perspective (Oldfield et al., 2012)

- The need of powerful server of handling the amount of data transferred and a stable and fast internet connection. (Petrisor, Marusteri, Ghiga, \& Schiopu, 2011)

- High cost of printing papers, human errors during marking, omission of students result, inadequate examination venues and invigilators, in a web-based examination system in Nigeria universities (Ndume, Dasuki, \& Ogedebe, 2014) 


\section{Coping with these challenges}

Based on the challenges in the use of e-assessment, it is necessary to establish steps to follow up on the lack of an e-assessment system in the future. The e-assessment system stores sensitive data such as students' personal data, assessment results and questions for each test. Data privacy, security and data integrity are therefore important requirements for each e-assessment system. The system must also provide authorization and authentication for both students and teachers to separate their access rights. The e-assessment system must provide a quick response after each student answers because the assessment time is limited. The e-assessment performance depends on the number of students enrolled. The most important factor affecting performance is the diversity of students assessed and concurrent assessment. All of these requirements introduce the need to implement an elastic system and can be measured for e-assessment (Ristov et al., 2013). If there are limitations to infrastructure it is necessary to consider an e-assessment delivery system with more than one web-based mechanism that can provide high-quality, media-rich, adaptive, standard assessments that work reliably across platforms and provide value to our customers (Byatt, 2014). Multiple strategies are important when improving assessment practice, including conceptual frameworks for assessment, supportive institutional policies and departmental initiatives, student engagement in the process and quality assurance procedures to evaluate the entire process (Oldfield et al., 2012). Using a fully customized system is more efficient and less time consuming. Assessment system with adaptive test creates and improves functions (Petrisor et al., 2011)

The successful implementation of e-assessment system requires other social factors such as infrastructural support, electricity supply, and skilled ICT workers (Ndume et al., 2014). A comprehensive outline of e-assessment system requirements for effective implementation are delivery system requirements, creating databanks and tests, control mechanisms in the test, e-assessment system feedback, program requirements, stability and speed of the on-line assessment system, security, reporting, support and training, evaluation of the on-line assessment system (Osuji, 2012).

Finally, e-assessment design is another important thing, starting from the content assessment, features used, scale, time and costs needed. It is necessary to prepare this e-assessment design in such a way that it can anticipate any problems that arise. There is a need to carry out preliminary research to analyze existing needs so that the e-assessment designed meets the expected needs.

\section{CONCLUSION}

The e-assessment system has become one of the requirements in higher education in the $21^{\text {st }}$ century. E-assessment provides many advantages in overcoming limitations in traditional assessments. This paper emphasizes the use of e-assessments in higher education along with the challenges faced and their solutions. The development of ICT in the assessment strategy contributes to e-assessement system in higher education. However, there are still many questions for lecturers, students, and institutions that pose challenges in the application of e-assessments related to validity and reliability, accuracy, fairness, security, infrastructure and human resources.

The things that need to be considered in the successful implementation of e-assessment are paying attention to the characteristics of e-assessment, designing assessments according to needs, and creating a complete and accessible assessment system for all.

\section{REFERENCES}

[1] Alruwais, N., Wills, G., \& Wald, M. (2018). Advantages and Challenges of Using e-Assessment. International Journal of Information and Education Technology, $\quad$ 8(1), 34-37. https://doi.org/10.18178/ijiet.2018.8.1.1008

[2] Asip, \& Wibawa, B. (2019). Experiential Learning Based Online Learning Development in the Jakarta Religion Affair Training Center. International Journal of Innovative Technology and Exploring Engineering (IJITEE), 8(6), 18-25.

[3] Beevers, C. (2011). What can e-assessment do for Learning and Teaching? Part 1 of a draft of current and emerging practice review by the e-Assessment Association expert panel. International Journal of E-Assessment, 1(2), 1-12.

[4] Brink, R., \& Lautenbach, G. (2011). Electronic assessment in higher education. Educational Studies, 37(5), 503-512. https://doi.org/10.1080/03055698.2010.539733

[5] Bukie, O. F. (2014). Understanding Technologies for E-Assessment : A Systematic Review Approach. Journal of Emerging Trend in Computer and Infromation Sciences, 5(12), 936-947.

[6] Byatt, R. (2014). Creating the Next Generation of E- Assessments in the Real World. Intenational Journal of E-Assessment, 1(1), 1-10.

[7] Charteris, J., Quinn, F., Parkes, M., Fletcher, P., \& Reyes, V. C. (2015) e-Assessment for Learning in Higher Education: Is it a wolf in sheep's clothing? Journal of Learning Development in Higher Education, (9). Retrieved from http://www.aldinhe.ac.uk/ojs/index.php?journal=jldhe\&page=article\&o $\mathrm{p}=$ view\&path $\% 5 \mathrm{~B} \% 5 \mathrm{D}=278$

[8] Council for the Curriculum Examination and Assessment. (2018). A Study of Learner and Centre views on the use of Electronic Assessment in Vocational, Professional and Technical Qualifications Contents. Retrieved

from https://accreditation.sqa.org.uk/accreditation/accreditationfiles/Research _and_Statistics/SQA_and_CCEA_Study_of_Learner_and_Centre_vie ws_on_use_of_Electronic_Assessment.pdf

[9] Crisp, G. (2011). Teacher's Handbook on e-Assessment. California: Australian Learning and Teaching Council Fellowship. Retrieved from http://transformingassessment.com/sites/default/files/files/Handbook_fo r_teachers.pdf

[10] Crisp, Geoffrey, Guàrdia, L., \& Hillier, M. (2016). Using e-Assessment to enhance student learning and evidence learning outcomes. International Journal of Educational Technology in Higher Education, 13(1), 18. https://doi.org/10.1186/s41239-016-0020-3

[11] Fontanillas, R. T., Carbonell, R. M., \& Catasús, G. M. (2016) E-assessment process: giving a voice to online learners. International Journal of Educational Technology in Higher Education, 13(20). https://doi.org/10.1186/s41239-016-0019-9

[12] Gikandi, J. W., Morrow, D., \& Davis, N. E. (2011). Online formative assessment in higher education: A review of the literature. Computers and Education, 57(4), 2333-2351. https://doi.org/10.1016/j.compedu.2011.06.004

[13] Hench, T. L. (2014). e-assessment: Past, Present, and Future. International Journal of E-Assessment, 1(1), 1-19. Retrieved from https://ijea.org.uk/index.php/journal/article/view/64

[14] Hettiarachchi, E., Huertas, M. A., \& Mor, E. (2015). E-assessment system for skill and knowledge assessment in computer engineering education. International Journal of Engineering Education, 31(2), 529-540. Retrieved from https://www.scopus.com/inward/record.uri?eid=2-s2.0-84925011817\& 


\section{Institutions}

partnerID $=40 \& m d 5=86 \mathrm{f} 6 \mathrm{a} 37 \mathrm{ad} 2757 \mathrm{a} 3 \mathrm{da} 45377 \mathrm{a} 8283 \mathrm{fea} 6 \mathrm{f}$

[15] Isaias, P., Miranda, P., \& Pífano, S. (2017). Framework for the analysis and comparison of e-assessment systems. In H. Partridge, K. Davis, \& J. Thomas (Eds.), Proceedings ASCILITE2017: 34th International Conference on Innovation, Practice and Research in the Use of Educational Technologies in Tertiary Education (pp. 276-283). QUEENSLAND.

[16] James, R. (2016). Tertiary student attitudes to invigilated, online summative examinations. International Journal of Educational Technology in Higher Education, 13(19). https://doi.org/10.1186/s41239-016-0015-0

[17] Joint Information Systems Committee (JISC). (2007). Effective Practice with e-Assessment. Information Systems Journal, 1-52. Retrieved from http://www.jisc.ac.uk/publications

[18] Jordan, S. (2013). E-assessment: Past, present and future. New Directions in the Teaching of Physical Sciences, 9(1), 87-106. https://doi.org/10.11120/ndir.2013.00009

[19] Khlifi, Y., \& El-Sabagh, H. A. (2017). A novel authentication scheme for E-assessments based on student behavior over E-learning platform. International Journal of Emerging Technologies in Learning, 12(4), 62-89. https://doi.org/10.3991/ijet.v12i04.6478

[20] Kuikka, M., Kitola, M., \& Laakso, M.-J. (2014). Challenges when introducing electronic exam. Research in Learning Technology, 22(22817). https://doi.org/10.3402/rlt.v22.22817

[21] Miguel, J., Caballe, S., Xhafa, F., \& Prieto, J. (2014). Security in Online Learning Assessment Towards an Effective Trustworthiness Approach to Support E-Learning Teams. 2014 IEEE 28th International Conference on Advanced Information Networking and Applications, 123-130. https://doi.org/10.1109/AINA.2014.106

[22] Ndume, H., Dasuki, S. I., \& Ogedebe, P. (2014). E-Assessment Systems For Universities In Developing Countries : A Nigerian Perspective, 7(4), 9-14.

[23] Nikolova, M. (2012). Characteristics and Forms of the Electronic Assessment of the Knowledge. NAUCHNI TRUDOVE NA RUSENSKIYA UNIVERSITET, 6.2, 93-98. Retrieved from conf.uni-ruse.bg/bg/docs/cp12/6.2/6.2-15.pdf

[24] Oldfield, A., Broadfoot, P., Sutherland, R., \& Timmis, S. (2012). Assessment in a Digital Age: A research review. Technology Enhanced Assessment: Review of the Literature. Retrieved from http://www.bristol.ac.uk/media-library/sites/education/documents/resea rchreview.pdf

[25] Osuji, U. S. A. (2012). The use of e-assessments in the Nigerian higher education system. Turkish Online Journal of Distance Education, 13(4), 1-13. https://doi.org/10.17718/TOJDE.25466

[26] Petrisor, M., Marusteri, M., Ghiga, D., \& Schiopu, A. (2011). Online Assessment System. Applied Medical Informatics, 28(1), 23-28.

[27] Ras, E., Whitelock, D., \& Kalz, M. (2016). The promise and potential of e-assessment for learning. Measuring and Visualizing Learning in the Information-Rich Classroom, (2), 21-40. https://doi.org/10.4324/9781315777979

[28] Ridgway, J., McCusker, S., \& Pead, D. (2004). Literature review of e-assessment. Futurelab, 7(4), 1-53. https://doi.org/10.1063/1.2756072

[29] Ristov, S., Gusev, M., Armenski, G., Bozinoski, K., \& Velkoski, G. (2013). Architecture and organization of e-Assessment cloud solution. IEEE Global Engineering Education Conference, EDUCON, 736-743. https://doi.org/10.1109/EduCon.2013.6530189

[30] Singh, U. G., \& (Ruth) de Villiers, M. R. (2017). An evaluation framework and instrument for Evaluating e-Assessment Tools. International Review of Research in Open and Distance Learning, 18(6), 164-185. https://doi.org/10.19173/irrodl.v18i6.2804

[31] Tinoca, L., Pereira, A., \& Oliveira, I. (2014). A Conceptual Framework for E-Assessment in Higher Education: Authenticity, consistency, transparency, and practicability. In Handbook of Research on Transnational Higher Education Management (In Siran M, pp. 652-673). IGI Global. https://doi.org/10.4018/978-1-4666-4458-8.ch033

[32] Whitelock, D., Reudel, C., \& Mackenzie, D. (2006). E-assessment : Case studies of effective and innovative practice a JISC. Jt. Inf. Syst. Comm, 184.

[33] Wibawa, B., \& Paidi. (2019). THE DEVELOPMENT OF BLENDED LEARNING BASED ON HANDPHONE FOR COMPUTER SYSTEM SUBJECT ON XI GRADE OF SMKN 1 BENGKULU CITY. Humanities \& Social Sciences Reviews, 7(3), 497-502. https://doi.org/https://doi.org/10.18510/hssr.2019.7373

\section{AUTHORS PROFILE}

My name is Pingkan Imelda Wuisan, and i am affaliated with Postgraduate Program, State University of Jakarta, 13120, Indonesia. My area of interest is learning.

I am Basuki Wibawa, currently affaliation is with Postgraduate Program, State University of Jakarta, 13120, Indonesia, for more details email me at :bwibawa@unj.ac.id. my area of interest is Students affairs and management. 